
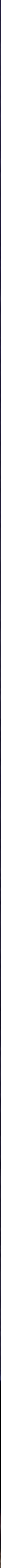


\section{DESAFIOS \\ DA EDUCAÇÃO FINANCEIRA}

\section{No Brasil, quase dois terços da população são analfabetos em finanças. Um treinamento contínuo e voltado mais para mudanças comportamentais do que para o ensino de conceitos pode ajudar a melhorar esse indicador.}

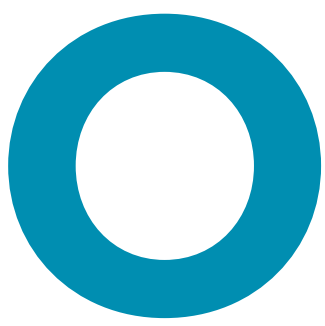

acesso da população brasileira aos serviços financeiros cresceu substancialmente nos últimos anos. Segundo dados do Banco Central, entre 2007 e 2016, o número de adultos com algum tipo de relacionamento bancário passou de 98 milhões para 138 milhões de pessoas - ou seja, de 66 para $87 \%$ da população adulta do país. Na mesma direção, o volume de crédito do sistema financeiro saltou de 26 para $47 \%$ do produto interno bruto (PIB) de 2003 a agosto de 2018 . Seguindo a mesma tendência, os cartões de crédito, outrora restritos a famílias de maior renda, disseminaram-se por todas as classes sociais e atualmente $33 \%$ do consumo total das famílias envolvem o seu uso como meio de pagamento.

Portanto, nos dias de hoje os serviços financeiros ocupam um espaço maior no cotidiano das famílias brasileiras, entretanto essa expansão do mercado não parece ter vindo acompanhada de um processo de educação financeira que permita o uso adequado de produtos e serviços. Conforme a Organização para a Cooperação e Desenvolvimento
Econômico (OCDE), educação financeira é uma combinação de consciência, conhecimento, habilidade, atitudes e comportamentos necessários para que o processo de decisão financeira seja adequado e promova o bem-estar individual.

\section{INDICADORES DE ALFABETIZAÇÃO FINANCEIRA}

Quando olhamos para o mundo, os números da educação financeira não são muito animadores. Na Standard \& Poor's Ratings Services Global Financial Literacy Survey, a pesquisa mais abrangente feita até o momento, envolvendo mais de 150 mil pessoas em mais de 140 países, apenas um em cada três adultos no mundo foram considerados alfabetizados financeiramente. Os respondentes precisavam conhecer ao menos três de quatro conhecimentos básicos de finanças: diversificação de risco (é mais seguro colocar seu dinheiro em um ou em múltiplos investimentos?), inflação (se nos próximos anos sua renda e os preços dobrarem, você será capaz de comprar mais, menos ou o mesmo do que hoje?), juros (se você tomar emprestado 100 dólares, qual o menor valor a pagar de volta entre duas opções, 105 dólares 


\section{ÍNDICE DE ALFABETIZAÇÃO FINANCEIRA EM DIFERENTES PAÍSES (EM \% DA POPULAÇÃO ADULTA)}

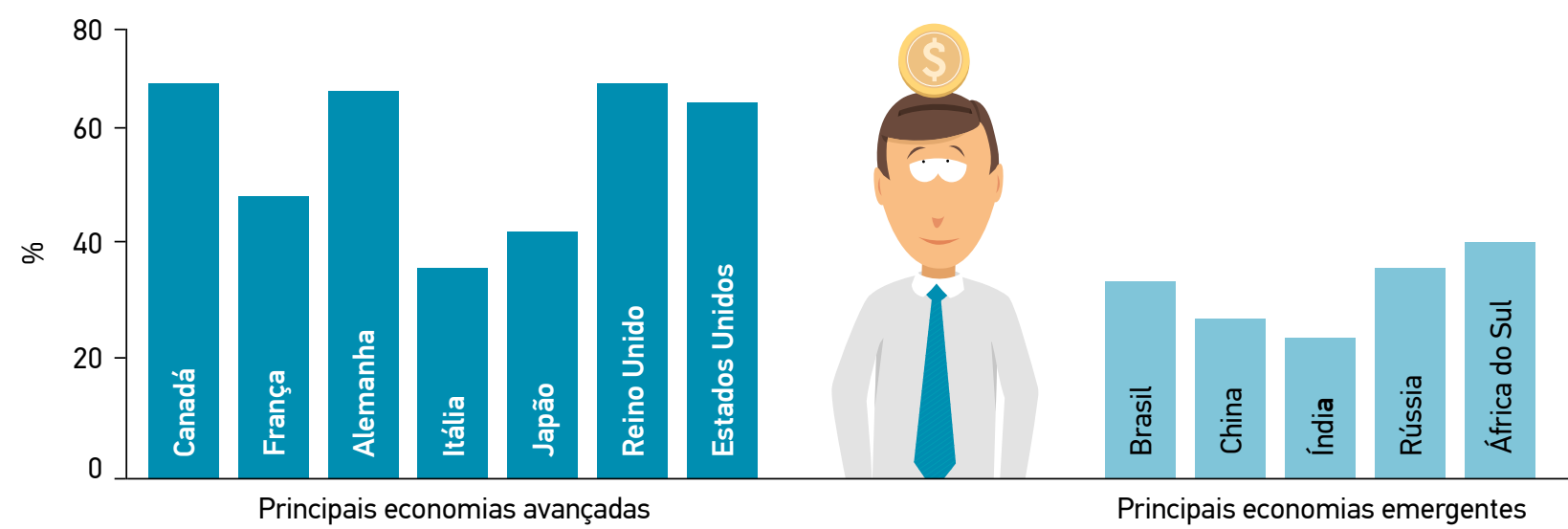

FONTE: S\&P GLOBAL FINLIT SURVEY

ou 100 dólares acrescidos de 3\%?) e juros compostos (se você fizer uma aplicação por dois anos à taxa de juros de $15 \%$ ao ano, o banco vai devolver no segundo ano mais ou o mesmo do que no primeiro ano?).

Há grandes variações entre países e regiões na pesquisa da Standard \& Poor's. Enquanto na média o índice de alfabetização financeira é de 55\% dos adultos nas economias mais avançadas (Canadá, França, Alemanha, Itália, Japão, Reino Unido e Estados Unidos), atinge apenas 28\% nos países chamados BRICS (Brasil, Rússia, Índia, China e África do Sul). No caso do Brasil, esse índice é de 35\% dos adultos. Dos $32 \%$ de brasileiros que possuem cartão de crédito, apenas $50 \%$ sabem responder corretamente a uma questão de taxas de juros compostos. Dessa forma, dificilmente conseguem entender a velocidade com a qual os juros compostos podem fazer a dívida aumentar.

Outro levantamento feito pela OCDE em 2017 define a alfabetização financeira como um fenômeno que combina conhecimento (de inflação, juros, diversificação e relação entre risco e retorno), comportamentos (controle financeiro, por exemplo, ao fazer orçamento; resiliência financeira, por exemplo, ao poupar e perseguir objetivos futuros; condições de fazer escolhas bem fundamentadas de produtos financeiros) e atitudes (foco exclusivamente no curto prazo ou preferência pela segurança no longo prazo). O levantamento foi realizado para os países do Grupo dos 20 (G20) mais Noruega e Holanda. De um total de 20 pontos, a média dos países do G20 foi 12,7 pontos. A pontuação do Brasil foi 12,1 , um pouco abaixo da média.

De acordo com essa mesma pesquisa, do total dos domicílios no Brasil, apenas $43 \%$ fazem regularmente orçamento familiar, índice que chega a $60 \%$ no caso da média dos países do G20. Chama também a atenção o índice de apenas $30 \%$ de poupadores ativos no Brasil, comparado com $64 \%$ na média dos países do G20, chegando a 79\% no Canadá, 83\% na França e 96\% na China. Outra informação importante é que $19 \%$ dos brasileiros recorrem a crédito para complementar a renda e cobrir os custos básicos de vida.

Vale dizer que, tanto para o Brasil quanto para os demais países, o desafio que se coloca envolve o próprio nível e a qualidade da educação básica. No Brasil, $27 \%$ da população compõe o grupo dos chamados analfabetos funcionais, enquanto $42 \%$ possui um nível de educação considerado elementar, ou seja, que permite apenas ler textos de complexidade média e fazer operações matemáticas de nível básico.

\section{INICIATIVAS DE EDUCAÇÃO FINANCEIRA NO BRASIL}

O Brasil vem fazendo, nos últimos anos, esforços para melhorar a educação financeira. O tema adquiriu status de política de Estado com a criação da Estratégia Nacional de Educação Financeira (ENEF). Com isso, surgiu o Comitê Nacional de Educação Financeira (CONEF), do qual fazem parte diversos órgãos públicos e organizações empresariais. 
A coordenação e execução dos programas ficam a cargo da Associação de Educação Financeira do Brasil (AEF-Brasil). Em 2018, foram mapeadas 1.393 iniciativas, a maior parte gratuita, percentual $72 \%$ maior do que o de 2013. Existem hoje no Brasil quatro grupos predominantes que atuam na educação financeira. O primeiro envolve iniciativas que privilegiam o ensino de crianças e jovens. $\mathrm{O}$ segundo tem como preocupação introduzir os principais temas financeiros à população. $\mathrm{O}$ terceiro inclui as iniciativas dirigidas a públicos específicos e oferece venda de treinamento e consultoria. $\mathrm{O}$ quarto abrange as iniciativas de empresas privadas para qualificar seus mercados de atuação e atender a seus clientes, fornecedores e demais stakeholders.

Em que pesem todo o esforço e o progresso já alcançado, ainda temos um longo caminho pela frente para melhorarmos a alfabetização financeira do brasileiro. $O$ país poderia ter metas de melhoria dos indicadores nessa área e um plano claro e continuado de como alcançá-las. Esse planejamento poderia envolver novos setores, de modo a estimular a inserção da educação financeira como um conteúdo a ser abordado por diferentes cursos e atividades educativas de forma transversal.

\section{ESTUDOS SOBRE EDUCAÇÃO FINANCEIRA}

Nos estudos acadêmicos, há divergências sobre os benefícios da educação financeira. Por um lado, as pesquisas mostram que consumidores que não conseguem entender 0 conceito de juros compostos incorrem em maiores custos de transação (tarifas), juros e dívidas e que pessoas com melhores habilidades financeiras fazem um trabalho melhor em termos de planejar e poupar para a aposentadoria. Por outro lado, há pesquisas que mostram que alfabetização financeira não tem efeito significativo sobre o comportamento financeiro dos indivíduos. É o caso de um estudo publicado na revista Management Science em 2014, que analisou mais de 200 estudos empíricos sobre os efeitos dos programas de educação financeira.

A despeito dos resultados contraditórios de diferentes estudos, algumas conclusões parecem ser geralmente aceitas. A primeira é que o maior tempo de treinamento leva a uma mudança maior e mais duradoura. Isso ocorre porque existe uma espécie de "curva de esquecimento". Ou seja, nossa capacidade de armazenar conhecimento vai declinando ao longo do tempo. Dessa forma, uma educação financeira continuada tenderia a gerar resultados mais consistentes. Uma segunda conclusão é que o autocontrole pode exercer papel fundamental no processo. A habilidade de resistir às tentações do

\section{A habilidade de resistir às tentações do presente pensando no amanhã é fundamental para o melhor uso dos produtos financeiros hoje disponíveis à população.}

presente pensando no amanhã é fundamental. Por fim, uma conclusão importante é que o trabalho de desenvolvimento de uma boa educação financeira pode ser mais bem-sucedido se focado em comportamento e habilidades em vez de em conceitos financeiros. Portanto, os aprendizados das ciências comportamentais devem ser incorporados aos treinamentos a fim de ampliar os efeitos sobre as decisões cotidianas.

\section{COMENTÁRIOS FINAIS}

Por fim, cumpre salientar o alerta de George Akerlof e Robert Shiller no livro Pescando Tolos. As soluções e produtos de mercado são fundamentais para o progresso alcançado pela humanidade, entretanto não produzem apenas o que nos faz bem ou que realmente queremos. O mercado é capaz de produzir e manipular nossos desejos e vontades de forma que podemos acabar comprando o que está sendo vendido, e não o que queremos. Nesse cenário, a educação financeira move apenas algumas peças no tabuleiro. Os valores éticos das empresas de serviços financeiros são essenciais para evitar um xeque-mate no bem-estar do consumidor.

\footnotetext{
PARA SABER MAIS

George Arthur Akerlof e Robert Shiller. Phishing for phools: the economics of manipulation and deception, 2015.

Banco Central do Brasil. Educação Financeira Funciona? Comentários ao Estudo Financial Literacy, Financial Education and Downstream Financial Behavior de Fernandes, Lynch Jr and Netemeyer (2014), 2015.

Daniel Fernandes, John G. Lynch Jr. e Richard G. Netemeyer. Financial literacy, financial education, and downstream financial behaviors. Management Science, v.60, n.8, 2014 doi.org/10.1287/mnsc.2013.1849

Leora Klapper, Annamaria Lusardi e Peter van Oudheusden. Financial Literacy Around the World: Insights from the Standard \& Poor's ratings services global financial literacy survey, 2015. Disponivel em: gflec.org/wp-content/uploads/2015/11/Finlit paper 16 F2

singles.pc

Annamaria Lusardi e Olivia S. Mitchell. The Economic Importance of Financial Literacy: Theory and evidence. Journal of Economic Literature, v.52, n.1, 2014. doi.org/10.3386 w18952

Associação de Educação Financeira do Brasil. $2^{\circ}$ Mapeamento Nacional das Iniciativas de Educação Financeira, 2018.

Organização para a Cooperação e Desenvolvimento Econômico. G20/OECD INFE Report on Adult Financial Literacy in G20 Countries, 2017.
}

JULIO LEANDRO > Mestre e doutorando em Administração de Empresas pela FGV EAESP > julio.leandro@fgv.edu.br

LAURO GONZALEZ > Professor e coordenador do Centro de Estudos em Microfinanças e Inclusão Financeira da FGV EAESP > lauro.gonzalez@fgv.br 